Revue bibliographique pour le domaine irano-aryen

\title{
Rémy Boucharlat. « Fire Altars and Fire Temples in the First Millennia BC/AD in the Iranian World: Some Remarks »
}

Laurianne Martinez-Sève

\author{
(2) OpenEdition \\ Journals \\ Édition électronique \\ URL : https://journals.openedition.org/abstractairanica/46302 \\ DOI : 10.4000/abstractairanica.46302 \\ ISBN : 1961-960X \\ ISSN : 1961-960X \\ Éditeur : \\ CNRS (UMR 7528 Mondes iraniens et indiens), Éditions de l'IFRI
}

\section{Référence électronique}

Laurianne Martinez-Sève, « Rémy Boucharlat. « Fire Altars and Fire Temples in the First Millennia BC/ AD in the Iranian World: Some Remarks » », Abstracta Iranica [En ligne], Volume 37-38-39 | 2018, document 38, mis en ligne le 30 décembre 2018, consulté le 21 septembre 2021. URL : http:// journals.openedition.org/abstractairanica/46302; DOI : https://doi.org/10.4000/abstractairanica. 46302

Ce document a été généré automatiquement le 21 septembre 2021.

Tous droits réservés 


\title{
Rémy Boucharlat. « Fire Altars and Fire Temples in the First Millennia $\mathrm{BC} / \mathrm{AD}$ in the Iranian World: Some Remarks »
}

\author{
Laurianne Martinez-Sève
}

\section{RÉFÉRENCE}

Rémy Boucharlat. « Fire Altars and Fire Temples in the First Millennia BC/AD in the Iranian World: Some Remarks » in Piotr Bielinski et al., Proceedings of the 8th International Congress on the Archaeology of the Ancient Near East, 30 April - 4 May 2012, University of Warsaw. Volume 1, Wiesbaden: Harrassowitz Verlag, 2014, p. 7-25

R. Boucharlat réexamine dans une perspective critique les critères permettant l'identification des temples et des cultes du feu en Iran et en Asie centrale. Elle pose souvent problème, car les pratiques cultuelles des populations zoroastriennes ne sont pas envisagées dans toute leur complexité et parce que les chercheurs se fient trop aux comparaisons avec le zoroastrisme d'époque sassanide ou celui d'époque moderne. Le rôle cultuel et le rôle rituel du feu ne sont pas assez distingués, ce qui conduit à interpréter comme des temples ou des autels du feu des constructions qui n'en étaient pas. En ce qui concerne l'Asie centrale, seules les structures attestant la conservation rituelle des cendres témoignent de l'existence de feux sacrés. Les temples à cella tétrastyle ne sont pas des temples du feu et les quelques exemples connus sont des édifices restés longtemps en fonction où les cultes du feu ont été introduits tardivement. En Iran, à l'exception peut-être du temple de Nush-i Jan où brûlait un feu permanent, les seuls bâtiments que l'on puisse associer au culte du feu sont d'époque sassanide. R. Boucharlat revient sur les chahar taq, que l'on interprète de manière trop systématique comme des temples du feu. Ces structures protégeaient parfois un feu sacré mais, quand c'était le cas, elles constituaient l'aménagement central d'une pièce 
fermée au plan cruciforme, et non le temple proprement dit. Les découvertes récentes de plusieurs temples du feu d'époque sassanide, qui sont présentées, aident à préciser leur apparence et leurs équipements.

\section{AUTEURS}

\section{LAURIANNE MARTINEZ-SÈVE}

Université de Lille 3, AOrOc-ENS 